\title{
LA EXPEDICIÓN DE LOS HERMANOS NODAL Y DIEGO RAMÍREZ DE ARELLANO. EL LEGADO EN LA CARTOGRAFÍA HISPANA DEL SIGLO XVII
}

\author{
RODRIGO MORENO J. a \& FRANCISCA RODRÍGUEZ B. ${ }^{b}$
}

\begin{abstract}
RESUMEN
Hace cuatro siglos los hermanos Bartolomé y Gonzalo Nodal, junto con el piloto Diego Ramírez de Arellano, fueron enviados por la corona hispana a los mares australes de América con la misión de verificar el hallazgo neerlandés del estrecho Le Maire y el cabo de Hornos. Tras corroborar los referidos hitos geográficos, rebautizándolos como estrecho de San Vicente y cabo de San Ildefonso, recorrieron el territorio descubriendo las islas Diego Ramírez, posteriormente regresando a España por la vía del estrecho de Magallanes en 1619. Las consecuencias de esta expedición no tuvieron el impacto esperado en la cartografía impresa europea, a excepción del referido archipiélago descubierto y otros topónimos menores, pero sí tuvieron influencia en la cartografía y la navegación española del siglo XVII, en particular en los derroteros náuticos manuscritos que se utilizaron en el Mar del Sur.
\end{abstract}

PALABRAS CLAVE: Bartolomé y Gonzalo Nodal, Diego Ramírez de Arellano, estrecho Le Maire, cabo de Hornos, cartografía.

\section{THE EXPEDITION OF THE BROTHERS NODAL AND DIEGO RAMÍREZ DE ARELLANO THE LEGACY IN HISPANIC CARTOGRAPHY OF THE 17TH CENTURY}

\section{ABSTRACT}

Four centuries ago the brothers Bartolomé and Gonzalo Nodal, together with the pilot Diego Ramírez de Arellano, were sent by the Spanish crown to the southern seas of America with the mission of verifying the Dutch discovery of the Le Maire Strait and Cape Horn. After corroborating the referred geographic landmarks, renaming them as estrecho de San Vicente and cabo de San Ildefonso, they traveled through the territory discovering the Diego Ramírez Islands and later returning to Spain by way of the Strait of Magellan in 1619. The consequences of this expedition did not the expected impact on European print cartography, with the exception of the aforementioned discovered archipelago and other minor place names, but it did have an influence

a Centro de Estudios Americanos Universidad Adolfo Ibáñez. $\boldsymbol{Z}$ rodrigo.moreno@uai.cl

b Universidad Adolfo Ibáñez. francisca.rodriguezb@uai.cl 
on Spanish cartography and navigation in the 17th century, particularly on the navigational nautical routes used in the South Sea.

KEY WORDS: Bartolomé and Gonzalo Nodal, Diego Ramírez de Arellano, Le Maire Strait, Cape Horn, cartography.

\section{INTRODUCCIÓN}

El hallazgo del cabo de Hornos por parte de los neerlandeses en 1616 significó la apertura hacia el Mar del Sur de un nuevo paso marítimo que en poco tiempo se transformó en nuevo corredor transoceánico del mundo moderno, alternativo al peligroso estrecho de Magallanes que, con sus angosturas, vientos y corrientes, presentaba enormes dificultades para la navegación de su tiempo. Y pese a que este nuevo cabo avistado por Schouten y Le Maire también ganó fama de difícil y peligroso para los marinos de su época, dicho nuevo espacio geográfico terminó por consolidarse como una ruta, desafiante pero útil, para los viajeros de los siglos XVII y XVIII.

Sin embargo, Hornos fue encontrado por navegantes que eran enemigos del imperio español y, por tanto, cuando Schouten y los sobrevivientes de la expedición arribaron a Ámsterdam el 1 de julio de $1617^{1}$, rápidamente la noticia se extendió por Europa, llegando a la corte hispana, la que se vio obligada a reaccionar puesto que de acuerdo a las primeras noticias, luego profundizadas en una detallada Relación que se publicó en $1618^{2}$, el nuevo paso correspondía a sus dominios y jurisdicción. Por lo tanto, en la corte de Madrid se tomó la determinación de organizar una expedición que tendría como objetivo reconocer los nuevos territorios aludidos por los neerlandeses, delinearlos

1 Jacob Le Maire falleció en el viaje de regreso a los Países Bajos en diciembre de 1616, mientras navegaba a bordo de la nave Amsterdam, perteneciente a la expedición de Joris van Spilbergen, con quien se había reunido en la actual Indonesia. Lach y Van Kley, 1993. Asia in the making of Europe. Chicago University Press, Chicago, p. 447.

2 Schouten, 1618. Journal Ofte Beschryvinghe van de wonderlicke reyse, ghaedaen door Willem Cornelisz Schouten van Hoorn, inde Jaren 1615, 1616, en 1617. Hoe hy bezuyden de Strate van Magekkanes een nieuwe Passagie tot inde groote Zuyzee onteckt en voort den gheheelen Aerdkloot angheseylt, heeft. Wat Eylanden, cartográficamente $\mathrm{y}$, al mismo tiempo, tomar posesión de este hallazgo que daba un giro relevante a la navegación austral y anticipaba la extensión del Imperio ${ }^{3}$.

Precisamente la reacción inmediata se debía a que el descubrimiento del Cabo significaba la apertura de una nueva ruta que podía relegar al estrecho de Magallanes como el único paso transoceánico, y por ende, la imposibilidad de controlar la circulación de naves extranjeras por aguas hispanas, la cual ya era deficiente dado el fracaso que había significado el poblamiento del Estrecho realizado por Pedro Sarmiento de Gamboa, y el fracaso del proyecto de emplazar fortificaciones como las diseñadas por Tiburcio Spannochi ${ }^{4}$.

Por lo anterior, si poco o nada había podido hacer España frente a las incursiones inglesas y neerlandesas en Magallanes hasta el paso de Joris van Spilbergen en 1615, el escenario se hacía más sombrío con el hallazgo del estrecho Le Maire y el cabo de Hornos, puesto que el paso al Mar del Sur se abría sin control posible. De ahí que la misión de los hermanos Nodal junto al piloto Diego Ramírez de Arellano, cobró un valor para España más allá de un simple descubrimiento geográfico.

\section{LA EXPEDICIÓN DE LOS NODAL: ANTECEDENTES Y DESARROLLO DE LA MISIÓN}

El referido hallazgo de Schouten y Le

vreemde volcken en wonderlicke avontueren hem ontmoet zijn. Willem Jansz, Amsterdam. La traducción en castellano se publicó en 1619 .

3 La anticipación del Imperio por medio de los mapas, así como la apropiación de tierras a través del papel, es una idea que planteó en su momento J.B. Harley. Cfr. Harley, 2005. La Nueva Naturaleza de los Mapas. Ensayos sobre la Historia de la Cartografía. Fondo de Cultura Económica, México, p. 85.

4 Zuleta, 2013. La fortificación del estrecho de Magallanes: un proyecto al servicio de la imagen de la monarquía. Revista Complutense de Historia de América, 39, 153-176. 
Maire de $1616^{5}$ marcó un hito importante para la navegación transoceánica europea, puesto que rompía definitivamente con el monopolio español en la periferia meridional, ya debilitado por la imposibilidad de controlar el estrecho de Magallanes, surcado en varias oportunidades por las potencias enemigas del imperio español, entre ellas, las naves de la Compañía Neerlandesa de las Indias Orientales. Como consecuencia de ello, el monarca Felipe III ordenó la organización de un viaje que comprobara la veracidad de los nuevos hallazgos que, de acuerdo a las noticias que comenzaron a arribar rápidamente a la Península, incumbían de manera directa a su gobierno y sus posesiones ultramarinas, en especial, cuando se hablaba de un nuevo paso interoceánico.

Antes de que se llevara a cabo el viaje, las autoridades hispanas buscaron la opinión de cosmógrafos expertos, como fue el caso de Juan Arias de Loyola ${ }^{6}$ quien envió una carta el 11 de julio de 1618 a la Junta de Guerra de Indias en la cual señalaba sus sugerencias con respecto a los instrumentos que se requerían utilizar y el papel que debía desempeñar el cosmógrafo que se sumaría a la expedición que estaba encomendando el monarca.

En una primera instancia se encargó el mando de la empresa a don Diego de Molina, quien luego de una serie de ofrecimientos, aceptó

5 La expedición, que formaba parte de la recién fundada Compañía Australiana, zarpó desde el puerto de Texel, Holanda, el 14 de junio de 1615. El viaje se inició con dos naves, el Eendracht (Concordia) y el Hoorn, con más de ochenta tripulantes en total.

6 Relación o parecer de don Juan Arias de Loyola, sobre el derrotero que debían llevar estas naos, designando el camino, los bajos, alturas y grados, etc., Archivo General de Indias, Sevilla, Fondo Patronato, 35, N. 5, R.4 (6). Este cosmógrafo realizó estudios que aportaron al saber cartográfico, específicamente sobre la utilización de implementos náuticos. Cfr. Esteban, 2002-2003. Las academias técnicas en la España del siglo XVI, Quadern's d'Historia de I'Enginyeria, V, 10-18.

7 Real Cédula al presidente de la Casa de la Contratación de Sevilla, encomendándole que dos carabelas al cargo de don Diego de Molina, vayan a reconocer y sondear el estrecho de Magallanes. San Lorenzo, 17 de septiembre de 1616. Archivo General de Indias, Sevilla, Fondo Patronato, 33, N.5, R.1. Se le ofrecieron dos carabelas con 15 soldados en cada una, marineros y artilleros que fuesen necesarios y un salario de 150 escudos al mes durante el tiempo que durase el viaje. A su regreso, se le daría el cargo de general de una el desafío7. Sin embargo, a pesar de lo acordado, Molina intentó modificar las condiciones pactadas lo cual retrasó el viaje ${ }^{8}$. Finalmente, los encargados de desarrollar esta empresa fueron los hermanos Bartolomé y Gonzalo Nodal junto al cosmógrafo Diego Ramírez de Arellano9.

Bartolomé, nacido en Pontevedra en 1574, había servido desde temprana edad en la Armada Real del Mar Océano, desempeñándose como capitán de galeones y navíos, y participando en comisiones de guerra. De este modo, fue adquiriendo prestigio no solo por su valentía sino también por su vasto conocimiento náutico. Por otra parte, Gonzalo Nodal, nacido en 1569, también había participado en un importante número de empresas marítimas, aunque su principal experticia tenía relación con la arquitectura naval ${ }^{10}$.

En cuanto a la elección del cosmógrafo, recayó en Diego Ramírez de Arellano, quien era natural de Xàtiva y reunía las capacidades para resolver importantes interrogantes en cuanto a mediciones astronómicas en los territorios a explorar, así como también para hacer un buen delineamiento de los posibles nuevos descubrimientos que tenían por misión corroborar.

Ya definido quiénes liderarían la expedición, comenzó la preparación de la empresa, para lo cual se trabajó en la construcción de dos carabelas, las que se decidió encargar en Lisboa, aprovechando

\section{de las flotas de Tierra Firme.}

8 Por las condiciones climáticas australes, se recomendaba que el viaje se iniciara en septiembre de 1617, sin embargo, no fue posible y la expedición terminó zarpando un año después.

9 El 2 de enero de 1618 Bartolomé presentó una Relación de Méritos y Servicios, solicitando gracias especiales al retorno del viaje que emprendería junto a su hermano. A través de la cédula del 20 de abril de 1618 se fijaron las condiciones y pagos a efectuarse, entre los que destacan: se les pagaría 60 ducados de sueldo al mes desde el momento en que comenzara la expedición y a su regreso se le otorgaría la plaza de almirante de la primera flota de las Indias. Archivo General de Indias, Sevilla, Fondo Patronato, 33, N.4, R.4.

10 Sobre más antecedentes biográficos, cfr. Vázquez de Acuña, 1996. La expedición de los hermanos Nodal (1618-1619), Boletín de la Academia Chilena de la Historia, 106, 31-51. Vicente, 2001. La expedición de los hermanos Nodal y el cosmógrafo Diego Ramírez de Arellano. Revista de Historia Naval, 73, 7-28. Portela, 1891. Apuntes biográficos acerca de los marinos Nodales, hijos de Pontevedra. Imprenta Landín, Pontevedra. 
la larga experiencia en construcción naval lusitana de este tipo de naves, y sacando así partido a la unión de los dos reinos, vinculados desde 1580 .

Terminadas las naves, siendo de 80 toneladas cada una, que se bautizaron como Nuestra Señora de Atocha y Nuestra Señora del Buen Suceso, los problemas más serios se presentaron al momento de concretar el enganche de la tripulación puesto que no hubo buena disposición de voluntarios y, por tanto, se tuvo que tomar medidas de fuerza para completar el número de hombres suficientes para cumplir con la misión. Finalmente, la solución estuvo en reclutar a la fuerza a marinos portugueses con el compromiso de entregarles 10 meses de sueldo por adelantado ${ }^{11}$. Además, se sumaron a la tripulación marinos neerlandeses, uno de los cuales, Jan de Witte, castellanizado a Juan Blanco, habría sido piloto en la expedición de Joris van Spilbergen y, por ende, pudo conocer a Schouten y Le Maire en el viaje de regreso a Ámsterdam. Este experimentado marino, junto con Peter de Leeter (Pedro de Letre), que también navegó con Spilbergen, Valentyn Jansz van Stettin y Pieter Michielsz van Catdoelen, quienes lo hicieron con Schouten y Le Maire ${ }^{12}$, conformaron un nutrido contingente de 8 pilotos que tuvo la expedición, entre los que se contaba el hispano Juan Manso, quien ayudaría a Ramírez de Arellano en la confección de las cartas de marear ${ }^{13}$.

Una vez entregadas las instrucciones del monarca ${ }^{14}$, las naves iniciaron su recorrido desde

11 Nodal y Nodal, 1621. Relación del viaje que por orden de su Mag. y acuerdo del real Consejo de Indias hizieron los capitanes Bartolomé García de Nodal y Gonzalo de Nodal ... al descubrimiento del Estrecho nuebo de S. Vicente y reconosimiento del de Magallanes. Imprenta de Fernando Correa, Madrid, p. 2; Consulta del Consejo de Indias a Su Majestad, sobre que se mandase proveer y pagar a los capitanes y gente de las dos carabelas de Bartolomé García Nodal, Madrid, julio de 1618. Archivo General de Indias, Fondo Patronato, 33, N.4, R.5 (2).

12 Martinic, 2018. Cuatro siglos del viaje de los hermanos Nodal a la Tierra del Fuego. Magallania, 46(2), 7-23, p. 8.

13 Cerezo, 1994. La cartografía náutica española en los siglos XIV, XV y XVI. Consejo Superior de Investigaciones Científicas, Madrid, p. 233.

14 Instrucciones dadas por Su Majestad a Bartolomé García de Nodal para el viaje al estrecho de Magallanes. San Lorenzo, 26 de agosto de 1618. Archivo General de Indias, Sevilla, Fondo Patronato, 33, N.4, R.5 (3).

15 Arribaron el 15 de noviembre del mismo año. Debieron el puerto de Lisboa el 27 de septiembre de 1618 con rumbo hacia la primera parada en Río de Janeiro, donde hicieron importantes reparaciones $y$ modificaciones a las naves ${ }^{15}$. En diciembre del mismo año tomaron rumbo hacia aguas magallánicas en busca de aquel estrecho avistado previamente por los neerlandeses.

Durante la travesía tuvieron algunas dificultades como, por ejemplo, no reconocer con detención las costas patagónicas como estaba estipulado en las instrucciones, aspecto que posteriormente hará notar el piloto Diego Ramírez ${ }^{16}$, así como también la imposibilidad de fondear en la bahía de San Julián, aunque sí se detuvieron en los estuarios de los ríos Santa Cruz y Gallegos. Finalmente arribaron al cabo de las Vírgenes, en la boca oriental del Estrecho el 15 de enero de $1619^{17}$.

Tras permanecer reconociendo la boca tanto por el norte como el sur, específicamente en el cabo del Espíritu Santo, decidieron continuar bordeando la costa este de Tierra del Fuego en demanda del posible estrecho, identificando primero el mal llamado canal de San Sebastián, a 13 leguas al sureste. Posteriormente continuaron hasta el cabo de Peñas, luego al cabo de Santa Inés, hasta llegar a la punta de San Diego, antesala de lo que sería el anhelado descubrimiento, el que Diego Ramírez describió en su relación de la siguiente forma: Con el viento fresco nos ivamos apartando de la costa y reparamos en que la tierra alta iva

permanecer unos días ya que ingresaba agua a los lugares de descanso de la tripulación, por lo que el gobernador les recomendó subir los puentes de las embarcaciones para enfrentar de buena manera los mares australes.

16 Ramírez, 1621. Reconosimiento [sic] de los estrechos de Magallanes y San Vicente, con algunas cosas curiosas de navegación. Institució Alfons el Magnànim, Valencia, p. 268, edición facsimilar de 2010 bajo la edición de Emilio Soler. Hemos tenido a la vista y comparado con el original conservado en la Biblioteca Nacional de España, Madrid, Mss. 3190, f. 20v. En la misma biblioteca hay un segundo manuscrito del autor con la signatura Mss. 3019 titulado Discurso y derrotero del viaje a los estrechos de Magallanes y Mayre y arrumbamiento de todas las costas que en esta navegación se anduvieron. Por ejemplo, cuando estuvieron en la boca del río La Cruz, Ramírez señala que Tuvimos muchas horas de calma con las quales uvo tiempo de reconocer el río con la chalupa, lo que no se hiço, esbozando una crítica a los hermanos Nodal que se repetirá varias veces a lo largo de su Relación.

17 Martinic, 2018, op. cit., p. 9. 
saliendo a la Mar del Norte y la baxa a la del Sur desenchasándose la una por la otra. Y como las señas que traímos de la tierra desde estrecho (que nos la dixo un piloto olandeses [sic] que venía con nosotros, que el mismo Mayre -primer descubridor deste estrecho- las avia dicho) era que la tierra del oeste dél era baxa y la del leste alta, allándonos casi con su altura con poco cuidado que tuvimos. Y a mui poco andar se nos descubrió la boca del Estrecho de Mayre, que después se le mudó el nombre en el de San Vicente, por aver llegado en el día de este santo a él ${ }^{18}$. Era el 22 de enero de 1619 y efectivamente el santoral católico recordaba a San Vicente Mártir, un santo hispano muerto en la persecución del emperador Diocleciano a comienzos del siglo IV, es decir, la elección no solo reconocía el azar del día, sino que, como lo insinúa el propio Ramírez, llegaron el día de un santo español ${ }^{19}$.

Posteriormente avistaron un cabo al que llamaron San Lorenzo, por ser otro santo español y que además, según la creencia popular a la cual adhería el piloto, era hermano de San Vicente. Luego continuaron al sur, pudiendo fondear en una bahía que llamaron del Buen Suceso, porque había sido la carabela de dicho nombre la que pudo hallar un buen fondo para lanzar ancla y un espacio para protegerse de los vientos que arreciaban ${ }^{20}$. Fue en este sector donde se produjo el primer encuentro directo con habitantes del lugar, posiblemente selk'nam orientales, los que a juicio de Martinic pertenecerían a la misma etnia que realizó los fuegos que observó Magallanes en su viaje de 1520 y que inmortalizó el topónimo de la isla ${ }^{21}$.

Tras unos días de pacífica estadía, el 27 de enero continuaron el viaje, no sin antes cruzar nuevamente el estrecho Le Maire, ahora San Vicente, con el fin de reconocerlo en detalle, identificando un cabo en la actual isla de los Estados, al que llamaron Setabense, y luego otro más al sur, en la propia isla, al que denominaron San Bartolomé ${ }^{22}$. Desde ahí nuevamente pusieron rumbo oeste hacia Tierra del Fuego, donde

18 Ramírez, 1621, op. cit., p. 276.

Ibidem.

Ibidem, p. 277.

Martinic, 2018, op. cit., p. 9.

Ramírez, 1621, op. cit., pp. 281-282.

3 Moreno, 2013. El cabo del Fin del Mundo: Hoorn y el bautizaron tres hitos geográficos: Farillones (sic), Monte Gordo e isla de San Gonzalo, a la que primero identificaron como cabo, continuando la exploración hacia Hoorn, al que reconocieron, previo avistamiento de unas pequeñas islas que bautizaron como San Ildefonso, mismo nombre con que pretendieron reemplazar el que le habían dado los neerlandeses al cabo de Hoorn, idea que como veremos más adelante, fue imposible que prosperara $^{23}$.

El hallazgo del cabo de San Ildefonso fue realizado el 5 de febrero de 1619, pero según cuenta el piloto Diego Ramírez fue 5 días más tarde, el 10 de febrero, que tras haber recorrido primero hacia el oeste, llamaron a un cabo San Juan, y luego de regresar hacia el sureste, descubrieron de paso una isla que llamaron Diego Ramírez, después volvieron a repetir el paso hacia el Mar del Sur, observando nuevamente el cabo de San Ildefonso, confirmando que se trataba del que habían descubierto Schouten y Le Maire. Ramírez reconoce que no estaban muy de acuerdo con el hallazgo, pero como él había dibujado el perfil de costa el 5 de febrero, cuando volvieron a pasar cinco días más tarde, dicho delineamiento permitió confirmar que habían llegado al lugar indicado. Y prueba de lo anterior es que, en la relación de los hermanos Nodal, el 5 de febrero se menciona que navegaron hasta el cabo de Udra, que es el mismo de San Juan, sin hacer mención que ese día habían avistado el cabo de Hornos, es decir, no fue sencilla la identificación y nada se menciona con relación a la posible ayuda de los pilotos neerlandeses que iban a bordo ${ }^{24}$.

Lo que sí es interesante es que a la descripción que se hace del Cabo, los Nodales añaden un perfil de costa que dice textualmente: cabo de San Ildefonso, de lejos parece isla ${ }^{25}$, intuición que años más tarde se confirmaría cartográficamente.

Luego de estas vicisitudes y aciertos, las naves tomaron rumbo hacia la boca occidental del estrecho de Magallanes, y si bien cruzarlo de oeste a este no fue tarea fácil, ya que hubo que

camino al Pacífico, Guerra (Ed.), Enigmas de las Américas. Geografía, Expediciones, Cartografía. Universidad de San Francisco, Quito, pp. 35-43, p. 38

24 Nodal y Nodal, 1621, op. cit., p. 38.

25 Ibidem, p. 40. 
sortear condiciones desfavorables de navegación, un mes más tarde, el 10 de marzo de 1619, las carabelas alcanzaron nuevamente el cabo de las Vírgenes, con lo cual completaron la primera circunnavegación de la isla de Tierra del Fuego, un hito que sobrepasaba con creces los objetivos del viaje.

Después emprendieron el regreso por la costa de Brasil hasta alcanzar, luego de casi tres meses y medio de navegación, la costa de la península ibérica, arribando primero al cabo de San Vicente, en Sagres, el 7 de julio de 1619, donde desembarcó Gonzalo García de Nodal, con el propósito de emprender viaje por tierra a Lisboa, donde se enteraron que estaba el monarca Felipe III $^{26}$. Ese mismo día la expedición continuó el viaje a Sanlúcar de Barrameda donde arribaron el 9 de julio, 9 meses y trece días después del zarpe, con un balance excepcional: con los objetivos cumplidos y regresando sin pérdidas humanas ni materiales, algo excepcional en la época.

Con Gonzalo en la corte en Lisboa, Bartolomé García de Nodal y Diego Ramírez se entrevistaron con el Duque de Medina Sidonia, señor de Sanlúcar, y luego emprendieron su traslado a Sevilla, donde arribaron el 15 de julio, presentándose ante el presidente y jueces de la Casa de Contratación. Finalmente, el 26 de julio, en palabras de Ramírez, nos partimos a la corte el capitán Bartolomé García de Nodal, capitán de las dos carabelas, y yo. Y el Consejo Real y Junta de Guerra de Indias, todo pleno, hiçe una copiossa relación de todo el viaje ${ }^{27}$.

Recibidas las noticias, vinieron los reconocimientos a quienes habían liderado la expedición, es decir, los hermanos Nodal y el piloto Diego Ramírez ${ }^{28}$, pero al mismo tiempo se iniciaron los preparativos para enviar una nueva expedición rumbo a Filipinas que ocupara la nueva ruta descubierta. De hecho, Gonzalo y

26 Ramírez, 1621, op. cit., p. 316, en el manuscrito, f. 63.

27 Ibidem, p. 317, en el manuscrito, f. 63r.

28 Carta acordada del Consejo a Diego de Vergara Gaviria, su receptor, dándole orden de pago de 200 reales para Diego Ramírez por lo que pagó a quien hizo una copia sobre el viaje por el estrecho de Magallanes, Madrid, 30 de agosto de 1619. Archivo General de Indias, Sevilla, Fondo Indiferente General, 428, L.35, f.101v.

29 Derrotero formado por los capitanes Gonzalo Nodal y Bartolomé García de Nodal, hermanos, y por el cosmógrafo
Bartolomé Nodal en conjunto con Diego Ramírez, redactaron un pequeño derrotero que tenía por finalidad indicar el camino para ir en demanda de las Filipinas, aunque a decir verdad, poco aportaba a la navegación en el Pacífico, aunque sí detallaba las distancias para llegar al cabo de San Ildefonso ${ }^{29}$, entendiendo con ello que tras sortearlo, la ruta a Manila se podía hallar teniendo precisión en la posición latitudinal: Y dará vista al cabo de San Ildefonso, y en passando este cabo se yra governando conforme dieren lugar los vientos procurando disminuir altura lo mas aprissa que se pudiere por lo menos hasta ponerse en altura de 53 grados desde la qual se governara al noroeste hasta llegar hasta la linea ${ }^{30}$.

De esta forma, solo cinco meses después del arribo de Nuestra Señora de Atocha y de Nuestra Señora del Buen Suceso, una flota que desde hacía tiempo se estaba preparando para viajar a Filipinas al mando del capitán general Lorenzo de Zuazola, y cuya ruta inicial sería el cabo de Buena Esperanza, finalmente zarpó con rumbo al estrecho de San Vicente, sustentando la decisión no solo en las noticias arribadas con los hermanos Nodal y Diego Ramírez, sino en la credibilidad profesional de este último, quien fue nombrado cosmógrafo mayor de la expedición ${ }^{31}$.

La escuadra zarpó el 21 de diciembre de 1619, con 1.792 personas a bordo, pero lamentablemente una mala maniobra provocó la pérdida de las naves almiranta y capitana a pocas millas del puerto de Cádiz en dirección a Gibraltar, con lo cual la misión fue considerada un desastre por la gran pérdida de vidas humanas y materiales, falleciendo entre otros el propio Zuazola. Diego Ramírez, quien salvó a nado, junto con los pilotos de la expedición fueron apresados y juzgados para determinar responsabilidades, de las cuales él fue finalmente absuelto, porque precisamente las decisiones de la ruta inicial tomadas por el

Diego Ramírez de Arellano, sobre ir desde Sanlúcar de Barrameda a Filipinas por los Estrechos de Magallanes y de San Vicente. Archivo General de Indias, Sevilla, Fondo Patronato, 263, N.1, R.11.

30 Ibidem, f. 3.

31 Soler, 2010. Diego Ramírez y los Hermanos Nodal, en: Ramírez, 1621. Reconosimiento de los Estrechos de Magallanes y de San Viçente. Institució Alfons el Magnàmin, Valencia, pp. 221-224. 
mando superior fueron erradas de acuerdo a su experiencia y testimonio ${ }^{32}$. De hecho, a finales de 1620 se le otorgó el puesto de Piloto Mayor de la Casa de Contratación, con lo cual llegaba a la cúspide de su carrera como cosmógrafo, ahora no solo con conocimientos teóricos, que los tenía de sobras, sino los prácticos, gracias al viaje con los hermanos $\mathrm{Nodal}^{33}$. Permaneció en el cargo hasta el 27 de mayo de 1624 fecha de su muerte en Sevilla ${ }^{34}$.

En cuanto a los hermanos Bartolomé y Gonzalo, nuevamente regresaron al mar, aunque esta vez separados, puesto que el primero, al mando de Nuestra Señora de Atocha se dirigió al Caribe para acompañar a la Flota de Tierra Firme, pero lamentablemente en el viaje de regreso a España falleció en el naufragio de su nave el 5 de septiembre de 1622 en los cayos de Matacumbé. Y en cuanto a Gonzalo, fue destinado a una flota que partiría a Chile por la nueva ruta descubierta, pero desafortunadamente dicha expedición naufragó en el Atlántico a finales del mismo año, falleciendo todos sus tripulantes ${ }^{35}$.

En síntesis, tanto los hermanos Nodal como Diego Ramírez de Arellano pasaron a la historia marítima hispana no solo por el reconocimiento que hicieron del estrecho Le Maire y el cabo de Hornos, descubiertos inicialmente por los neerlandeses, sino también por los significativos aportes a la náutica y a la cartografía de su tiempo, en especial gracias a la precisión entregada por el cosmógrafo Ramírez de Arellano, quien aportó con registros y anotaciones bastante certeras para la época, como por ejemplo, una exhaustiva tabla de variaciones, las cuales observó a través de la aguja de marear en los diferentes lugares recorridos, así como cálculos que realizó sobre la latitud por alturas extra meridianas, tema donde se observa el mayor dominio por parte del cosmógrafo. Por ejemplo, en el manuscrito, en más de una ocasión expone, y también critica,

32 Ibidem, p. 222. Cfr. Gil, 1989. Mitos y utopías del Descubrimiento. Alianza editorial, Madrid, Tomo II, El Pacífico, p. 205.

33 Soler, 2010, op. cit., p. 224

34 Ibidem, pp. 239-240.

35 Fernández de Navarrete, 1851. Biblioteca Marítima Española. Imprenta de la viuda de Calero, Madrid, pp. 218 y 596.

36 Sobre el aporte científico de los cálculos de Ramírez, los métodos desarrollados hasta ese momento. Sus objeciones se centraban principalmente en que, si bien los diversos métodos conocidos eran brillantes matemáticamente, no ocurría lo mismo en la práctica.

De hecho, su sistema lo llevó a calcular la distancia en leguas exactas recorridas durante toda la expedición, las que sumaron 5.878 en total $y$, paralelamente, entregó un detalle de las distancias entre un punto y otro. Además, agregó interesantes anotaciones, por ejemplo, de la ballestilla y el astrolabio ${ }^{36}$. Por lo anterior, sin restar méritos a los hermanos Nodal como responsables de la expedición, la presencia de un cosmógrafo de fuste como lo era Ramírez de Arellano permitió legar un buen material para las futuras empresas, siendo el cartográfico a través del mapa publicado en 1621 el que finalmente gravitó en el resto del siglo XVII entre los marinos hispanos, pese a que nunca se hizo público el mapa original que él delineó. Incluso, si se hubiese seguido al pie de la letra las instrucciones del monarca en cuanto a confeccionar un derrotero específico de todas las costas, objetivo que el cosmógrafo siempre tuvo presente y no así los hermanos Nodal, el resultado científico hubiese sido mucho más contundente. Por ello, Ramírez dejó en evidencia sus diferencias con los capitanes, a tal punto que en la última parte de su trabajo manuscrito redactó un capítulo titulado erores [sic] del libro de los capitanes Nodales $^{37}$, en más de una ocasión en cuanto a que pocas veces se le permitió disponer del tiempo oportuno para reconocer las costas y los estrechos, aunque ello se podría entender en cuanto a la visión de Bartolomé García de Nodal, de alcanzar los objetivos centrales en los tiempos óptimos para la navegación y la seguridad de quienes estaban bajo su mando. Por otra parte, también hay que reconocer que Ramírez casi no es mencionado en la Relación publicada por los

véase Díaz, 2013. Aportaciones al cálculo de la latitud en la náutica española de principios del siglo XVII contenidas en el manuscrito de Diego Ramírez de Arellano Reconocimiento de los estrechos de Magallanes y San Vicente, con algunas cosas curiosas de navegación (1621), Asclepio. Revista de Historia de la Medicina y de la Ciencia, 65(2), 1-14.

37 Ramírez, 1621, op. cit., pp. 445-460. En el manuscrito, ff. 167-181v. 
Nodal en 1621, por lo que podríamos estar en presencia de una disputa que era más profunda de la que se percibió en su tiempo ${ }^{38}$.

\section{CONSECUENCIAS CARTOGRÁFICAS DEL VIAJE}

Puede resultar sorprendente que solo un año después del regreso de la expedición de los hermanos Nodal y Diego Ramírez, el rey Felipe III, a través de su Consejo de Indias, aprobase la publicación de la Relación del viaje, el que saldría a la luz en 1621. Para entonces, una política de la corona hispana era mantener con gran reserva las derrotas de sus expediciones y el resultado cartográfico de las mismas, con el fin de que espacios tan estratégicos como lo era la periferia meridional de América, no fuesen conocidos en detalle por las potencias enemigas ${ }^{39}$.

Sin embargo, tras el hallazgo del estrecho Le Maire y el cabo de Hornos por parte de la expedición de los referidos Schouten y Le Maire, debe haber parecido más sensato buscar la apropiación de un espacio a través de universalizar las noticias de esta expedición, considerada exitosa en pro de los intereses del imperio español, puesto que no solo se había comprobado la existencia de dicho estrecho y cabo, sino que los habían renombrado, en una estrategia de apropiación toponímica y, además, se había verificado que dichos territorios formaban parte integral de su soberanía.

Pero hay otra razón que explicaría el porqué de su publicación oficial y que tiene relación con el detallado contenido de la misma, de enorme valor para las futuras incursiones hispanas al Pacífico americano y las Islas Filipinas. De hecho, en la declaración que hace el Licenciado Juan de Xerez, escribano de Cámara, y que se publica en la Relación, se señala que el contenido de la obra sería provechoso para quien hubiere de hacer aquel viaje $e^{40}$, dando a entender precisamente que la universalización de su contenido permitiría que las noticias contenidas en la

38 Ramírez es mencionado a propósito del relato de la cacería de leones marinos. Cfr. Firbas, 2012. El mapa y sus sombras: La Relación de los hermanos Nodal al estrecho de Magallanes (1621), Faúndez y Lermanda (Eds.), El laberinto y el hilo. Homenaje a Gilberto Triviños. Editorial Universidad de Concepción, Concepción, 2012, p. 37.

39 Rodríguez, 2018. El poder está en el Mar. La expedición de obra fuesen referencia para futuros viajeros, más aún si se toma en consideración que solo un mes antes de la firma de la autorización, una expedición que se aprestaba a repetir el viaje por el Sur, en demanda de las Filipinas, la de Zuazola, había naufragado al poco de partir con la pérdida de cientos de hombres, incluido el capitán general que la dirigía ${ }^{41}$.

Estas trágicas experiencias debieron influir en posibilitar la publicación de todos los detalles del viaje, así como de recomendaciones que hicieron Bartolomé y Gonzalo García de Nodal de su periplo por aguas atlánticas rumbo al nuevo estrecho descubierto. Además, refuerza este argumento de que el escrito publicado tenía por finalidad servir de ayuda a los navegantes, el que los mismos autores de la Relación señalan cuál era el objetivo de la publicación: solo pretendemos (como lo muestra el título) dar con breve y diaria relación, verdadera, clara, y distinta noticia de nuestro viaje, para universal provecho ${ }^{42}$, para salvar vidas.

Y aún más, en unas "advertencias" preliminares al relato, los autores entregan una información que sería vital para las futuras navegaciones porque transmitía una experiencia que no podía pasar por alto: Aviendo visto y entendido algunas circustancias y dificultades de este viaje, será cosa muy acertada y conveniente al servicio de su Magestad, mandar que las armadas y galeones que huvieren de navegar por los estrechos, para pasar a la Mar del Sur, partan de España en principio de agosto por lo menos $^{43}$, dato que servía para calcular la travesía de manera correcta y así pasar por la zona austral durante los meses de diciembre y enero.

Es decir, los autores hacían pública una información relevante que podía ser leída por futuros pilotos de la corona hispana; sin embargo, nada impediría que también estas noticias llegaran a manos foráneas, específicamente, a los enemigos de España, riesgo que al parecer se quería asumir en pro de fortalecer los intereses del Rey, de acuerdo a las razones antes esgrimidas, haciendo recordar que

los Hermanos Nodal (1618-1619), Obradoiro de Historia Moderna, 27, 293-320, p. 314.

40 Nodal y Nodal, 1621, op. cit. Fe de aprobación, p. 3.

41 Soler, 2010, op. cit., p. 223.

42 Nodal y Nodal, 1621, op. cit., p. 12.

43 Ibidem, p. 16. 
así como la Corona vio en el hallazgo del estrecho de Magallanes un tema de Estado, así también vio en este otro estrecho, la misma relevancia estratégica.

Para cuando la edición salió a la luz, fallecía en Madrid el rey Felipe III, por lo que la obra de los Nodal se hizo visible en el mundo bajo el reinado de Felipe IV, quien a solo días de cumplir los 16 años de edad asumió el poderoso imperio español y los complejos desafíos de conservar los lejanos territorios ultramarinos, pero con la mente en las guerras religiosas iniciadas en los territorios del Sacro Imperio Romano Germánico en 1618.

Y si la obra efectivamente era un extraordinario relato de la expedición antes referida, notable fue la inclusión en el texto final de un mapa elaborado por el cartógrafo portugués Pedro Teixeira y grabado por el francés Jean de Courbes, quien ese mismo año había iniciado sus trabajos en Madrid. Esta pieza cartográfica se basaba principalmente en las descripciones realizadas por los hermanos Nodal y fundamentalmente a partir del bello mapa que el piloto Diego Ramírez había realizado al regreso de España en 1619, de acuerdo a sus experiencias $y$ anotaciones contenidas en su manuscrito Reconosimiento de los estrechos de Magallanes y San Viçente, el que estaría imposibilitado de ser publicado de acuerdo a la aprobación del libro de los hermanos Nodal, que tendrían privilegios exclusivos por 10 años $^{44}$. Pero es verdad que a la vista también debió influir, y mucho, la cartografía resultante de la expedición de Schouten, quien sobrevivió en su travesía de circunnavegación y regresó con Spilbergen a Ámsterdam (Fig. 1).

Como se señaló en un comienzo, el retorno de Schouten a los Países Bajos posibilitó la pronta

44 El mapa de Teixeira no está presente en todos los ejemplares de la edición de 1621, por lo que se sustenta la idea de que fue censurado por orden de Felipe IV, por constatar la valía de su información, en un cambio de criterio con relación a la primera aprobación de su padre. Sobre este punto, tanto la curaduría de The John Carter Brown Library, como otros expertos, lo sostienen.

https://jcb.lunaimaging.com/luna/servlet/detail/JCBMAP S 1 1 4185 102273:Reconocimiento-delos-estrechosde-M?quq=q:nodal\&mi=1\&trs=3.

Cfr. Barry Lawrence Ruderman, https://www.raremaps. com/gallery/detail/56647/relacion-del-viage-que-pororden-de-su-magestad-y-acuerdo-nodal-nodal

45 Kroon (Ed.), 2016. Atlas of Cape Horn. The cartography of Southern South America 1500-1725. Thoth Publishers, Bussum, p. 121. publicación de su Relación, en la cual se incorporó un mapa de la travesía por el estrecho Le Maire y el cabo Hoorn, con toponimia definida por la expedición, situando el cabo en la posición latitudinal sur en los $57^{\circ} 48^{\prime}$, pero con imposibilidad de obtener la posición longitudinal ${ }^{45}$.

Esta obra llegó a España y estuvo en manos de las autoridades y de los propios miembros de la expedición, por lo que fue la primera referencia a la hora de delinear el territorio explorado. Sin embargo, otros ejemplares circularon en la península ibérica entre 1618 y 1621 y tuvieron que influir en la cartografía náutica española.

El primer caso fue la aparición de la carta realizada en 1618 por Antonio Moreno, y que se titula Carta de la Región Magallánica, Tierra del Fuego y Estrecho de Le Maire ${ }^{46}$. Moreno era catedrático de cosmografía, cosmógrafo y arqueador de navíos, y posteriormente llegó a ser Piloto Mayor interino de la Casa de Contratación, reemplazando precisamente a Diego Ramírez de Arellano el año de su muerte en $1624^{47}$. Él tuvo la ocasión de conocer a Witte cuando éste llegó a España para sumarse a la expedición de los Nodal, y como el Presidente de la Casa de Contratación encargó al neerlandés que hiciera un padrón, Antonio Moreno fue el encargado de hacer la versión definitiva y entregarla al Consejo de Indias ${ }^{48}$. En cuanto al bosquejo de Witte, posiblemente sea el que se conserva en el Archivo General de Indias, que se titula Carta náutica del Estrecho de Magallanes y del de Le Maire, y áreas aledañas, realizada presumiblemente entre 1617 y 1618 , puesto que la similitud con la carta de Moreno es evidente, incluida la toponimia ${ }^{49}$.

46 Archivo del Museo Naval de Madrid, 53-B-9. También en Archivo Histórico Nacional, Madrid, Colección Documentos de Indias, Car.1, N.4. Citado en Guillén y Tato, 1942. Monumenta Chartographica Indiana. Ministerio de Asuntos Exteriores, Madrid, p. 86; Martinic, 1999. Cartografía Magallánica 1523-1945. Ediciones de la Universidad de Magallanes, Punta Arenas, p. 38.

47 Pulido, 1950. El Piloto Mayor. Pilotos mayores, catedráticos de cosmografía y cosmógrafos de la Casa de Contratación de Sevilla. Escuela de Estudios Hispano Americanos, Sevilla, p. 753.

48 Ibidem, p. 763.

49 Cfr. Martinic, 1972. Cartografía derivada de los descubrimientos y exploraciones holandeses en la región Magallánica. Comentario y catálogo preliminar. Anales Instituto de la Patagonia, III(1-2), 5-30, p. 16. 


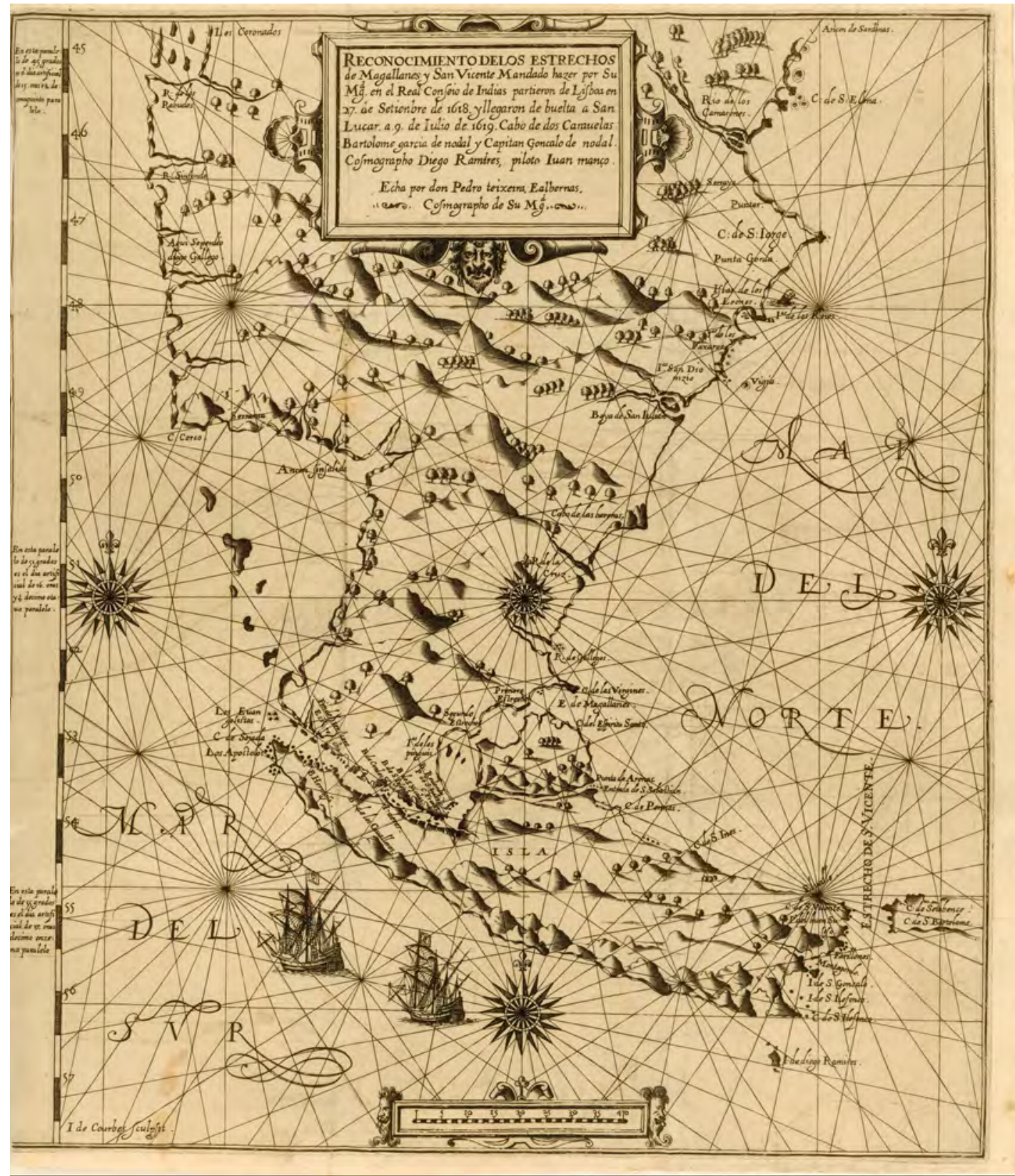

Fig. 1. Mapa de Pedro Teixeira, 1621,

basado en las cartas manuscritas de los hermanos Nodal y de Diego Ramírez de Arellano. Cortesía de The John Carter Brown Library Collection.

Y junto a estas cartas, la carta que pudo influir en los Nodal y Ramírez de Arellano fue la que realizó el flamenco Peter de Leeter, originario de Amberes, titulada Carta de la Tierra del

50 Kroon (Ed.), 2016, op. cit., p. 127. Peter de Leeter había sido tripulante de la expedición de Joris van Spilbergen
Fuego con los estrechos de Magallanes y Le Maire, datada en $1618^{50}$, es decir, antes de la travesía de los Nodal y Ramírez, aunque llama la atención que la toponimia no sea completamente

entre 1614 y 1617. La datación de este mapa en el Atlas está errada, porque indica 1619. 
coincidente con la neerlandesa de Schouten ${ }^{51}$, lo cual se explicaría por la ayuda que habría recibido de algún portugués que le colaboró con los topónimos, y porque el autor no participó en la travesía de Schouten y Le Maire ${ }^{52}$.

A este corpus de cartografía previa al viaje de los Nodal, hay que sumar otra carta publicada en 1619 y que es casi similar a la editada en la obra de Schouten, la que bajo el título Carte du Destroict trouve et passe par Jacq. Le Maire au dela du Destroict de Magallanes vers le Zudest, se presentaba muy coincidente en toponimia a la otra publicada, pero con mejoras en el delineamiento del territorio y la representación de los espacios, y por ende, cercana a la de Moreno y la del propio Ramírez y Teixeira ${ }^{53}$.

Por lo anteriormente descrito, la base del conocimiento del mapa realizado por Ramírez de Arellano y publicado por el cosmógrafo portugués Pedro Teixeira se sustentaba en una cartografía previa, a lo que sumaba la experiencia de navegación y reconocimiento del territorio que habían hecho los hermanos Nodal y el piloto setabense, de ahí se explica la valiosa pieza resultante en la publicación de 1621. Sin embargo, si bien la cartografía extranjera, en particular la neerlandesa, continuó su desarrollo apoyada en una fuerte presencia en la industria tipográfica y en la información de nuevas empresas como la de L'Hermite, quien cruzó el estrecho Le Maire el 2 de enero de 1624, en el caso hispano, los naufragios antes referidos como el de Zuazola y el del propio Gonzalo García de Nodal, imposibilitaron que nuevos navegantes ratificaran y profundizaran en el reconocimiento del territorio, por lo que el mapa de los hermanos Nodal, como se le conoció al impreso de 1621, siguió siendo el referente en las décadas siguientes, sin mayores modificaciones ni progresos.

51 Carta de la Tierra del Fuego con los estrechos de Magallanes y Le Maire, c. 1618. Real Academia de la Historia, C-003086.

52 Guillén y Tato, 1940. Una carta inédita del estrecho de Le Maire, e identificación de otras dos anónimas del siglo XVI. Revista de Indias, I, 35-58.

53 Martinic, 1999, op. cit., p. 241.

54 Moreno y Ortiz, 2018. Un Derrotero del Mar del Sur. El Pacífico americano a fines del siglo XVII. Biblioteca Nacional, Centro de Estudios Barros Arana, Santiago, p. 31. Esta es una edición facsímil de la cartografía del Derrotero del Mar del Sur, cuyo original se conserva en el Museo Naval de Madrid, Ms. 1202.
Lo arriba afirmado tiene sustento en la revisión de derroteros náuticos españoles que datan del siglo XVII y que fueron la base geográfica sobre la que trabajaron los pilotos del Mar del Sur, desde Acapulco hasta el cabo de Hornos. Así, como ejemplo, en el caso del Derrotero del Mar del Sur realizado en El Callao en 1675, sacado de los diferentes quadernos que an escrito y usado los mas clasicos y experimentados pilotos desde Mar del Sur ${ }^{54}$, la representación del territorio austral deja en evidencia que aún para esas fechas los navegantes hispanos basaban su conocimiento náutico en la experiencia de los hermanos Nodal y Diego Ramírez, a tal punto que todavía se utilizaba toda la toponimia establecida en la travesía de 1618 y 1619 , siendo llamativo el que, para ese tiempo, aún no quedaba al descubierto que el cabo de Hornos era una isla y no la punta de Tierra del Fuego, error que ya se había ido superando en la cartografía neerlandesa ${ }^{55}$ (Fig. 2).

De igual forma, se hace evidente en el Derrotero que la ruta que utilizaban los navegantes españoles era la del estrecho de San Vicente y cabo de San Ildefonso, puesto que la representación del estrecho de Magallanes es tan precaria que hubiese sido imposible navegar con esa carta náutica. Los derroteros eran instrumentos vitales en la navegación de los pilotos, por lo que esta síntesis de diferentes cuadernos de pilotos debió tener el estado del arte de su tiempo y todo indica que el estrecho de Magallanes no estaba en uso regular para la fecha de datación del mapa ${ }^{56}$.

Otro ejemplo de derrotero náutico es el Derrotero General del Mar del Sur también realizado en El Callao en 1730 por Manuel Joseph Hurtado, pero que contiene información del siglo XVII. En el caso del estrecho de Magallanes, la información procede

55 Sobre la influencia del viaje de los hermanos Nodal en la cartografía europea no española, cfr. Rodríguez, 2017. Expedición de los Hermanos Nodal y el cosmógrafo Diego Ramírez: el fin del ciclo de los grandes descubrimientos en los mares del Sur. Tesis para optar al grado de Magíster en Historia, Universidad Adolfo Ibáñez, Santiago, pp. 113127.

56 Moreno y Ortiz, 2018, op. cit., p. 523. Esta carta del estrecho de Magallanes, f. 573 del original que se conserva en el Museo Naval de Madrid, es la misma que Guillén y Tato incorporó en su Monumenta Chartographica Indiana, mapa 5, pero en ese momento el manuscrito pertenecía a la librería Barbazán de Madrid. 


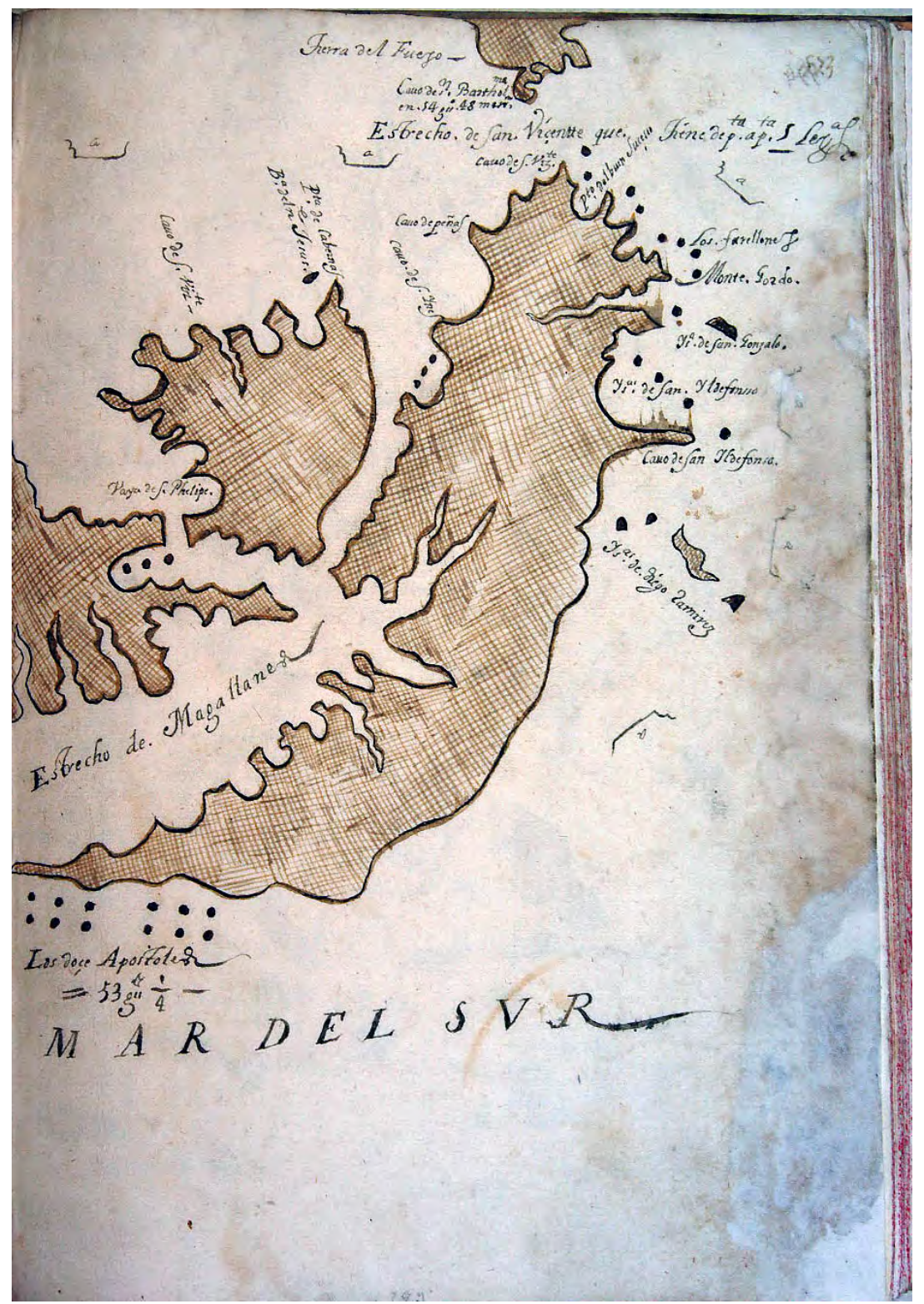

Fig. 2. Mapa del estrecho de Magallanes en donde se observa la mayor importancia toponímica del estrecho Le Maire y el cabo de Hornos.

Derrotero del Mar del Sur, 1675 Museo Naval de Madrid, Ms. 1202.

del Derrotero del viaje de Antonio de Vea de 1676, y en dicha pieza cartográfica se aprecia la total influencia del mapa del viaje de los Nodal y Diego Ramírez, con detalles de la toponimia, incluyendo el cabo de Udra, tal como lo llaman los hermanos en la edición de $1621^{57}$ (Fig. 3).

57 Ortiz (Ed.), 1993. Derrotero General del Mar del Sur del capitán Pedro Hurtado de Mendoza, hecho por el
Un tercer ejemplo lo hallamos en uno de los derroteros náuticos que se conservan en la Biblioteca Nacional de España, en Madrid, identificado como Mapas de las costas de América en el Mar del Sur, desde la última población de españoles en ellas, que es la ciudad de Compostela, y que representa

Capitán Manuel Joseph Hurtado en el puerto del Callao, año 1730. Dirección de Intereses Marítimos, Lima, p. 128. 


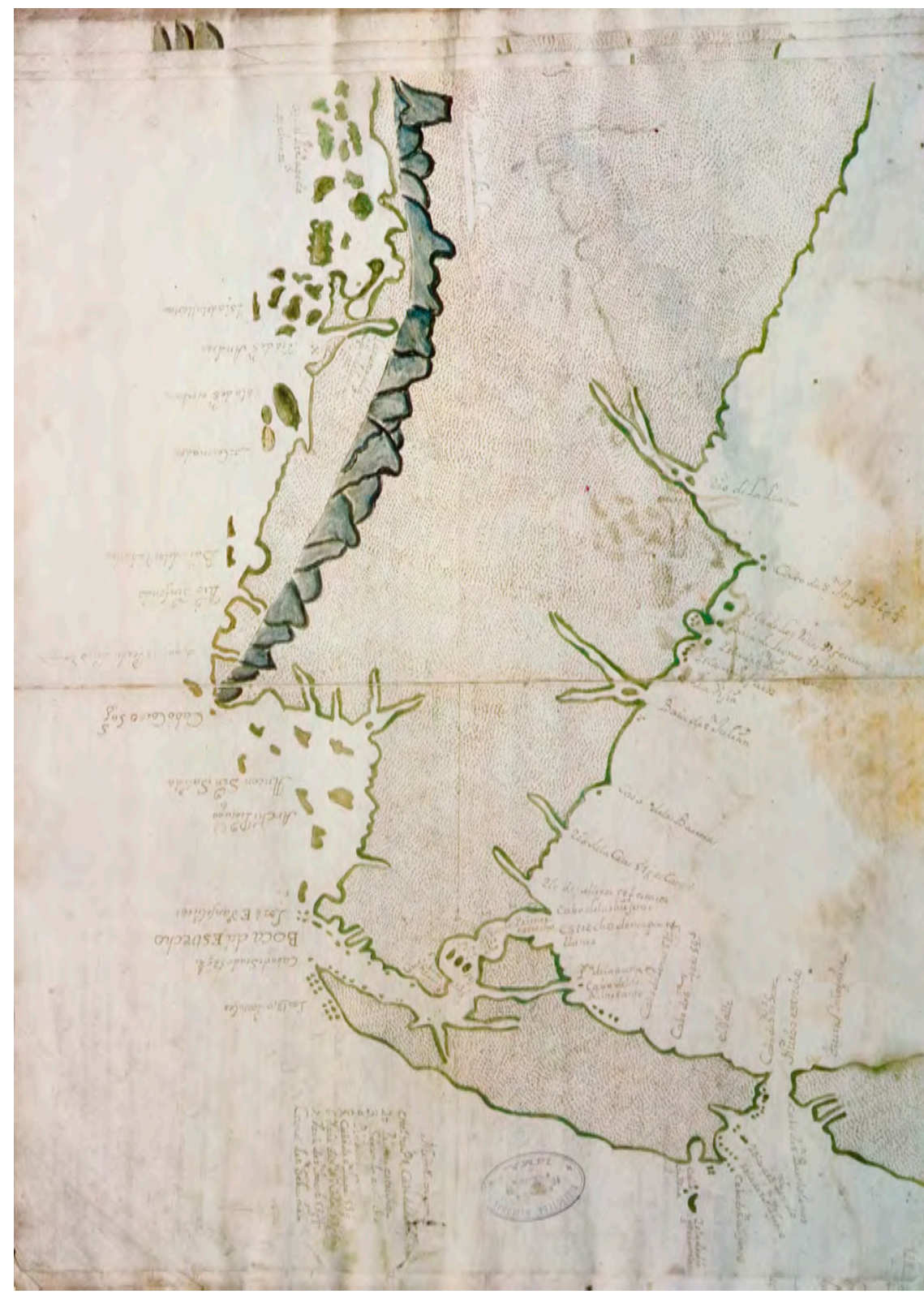

Fig. 3. Mapa del estrecho de Magallanes y Tierra del Fuego. Esta valiosa pieza cartográfica se encuentra hoy perdida por robo. Derrotero General del Mar del Sur, 1730.

Biblioteca Nacional, Lima.

toda la costa desde Acapulco a Tierra del Fuego ${ }^{58}$. En el mapa correspondiente a Magallanes y Tierra del Fuego, nuevamente se comprueba que toda la toponimia en el extremo austral está basada en el

58 Mapas de las costas de América en el Mar del Sur, desde la última población de españoles en ellas, que es la ciudad de Compostela. Biblioteca Nacional de España, viaje de los hermanos Nodal, incluyendo el cabo de Udra, prueba de que el libro de 1621, en donde se incluyó el perfil de costa de dicho cabo, seguía influyendo en los navegantes, dejando entrever por

Mss. 2957, con posible datación hacia mediados del siglo XVII, pero con intervenciones posteriores a 1685. 


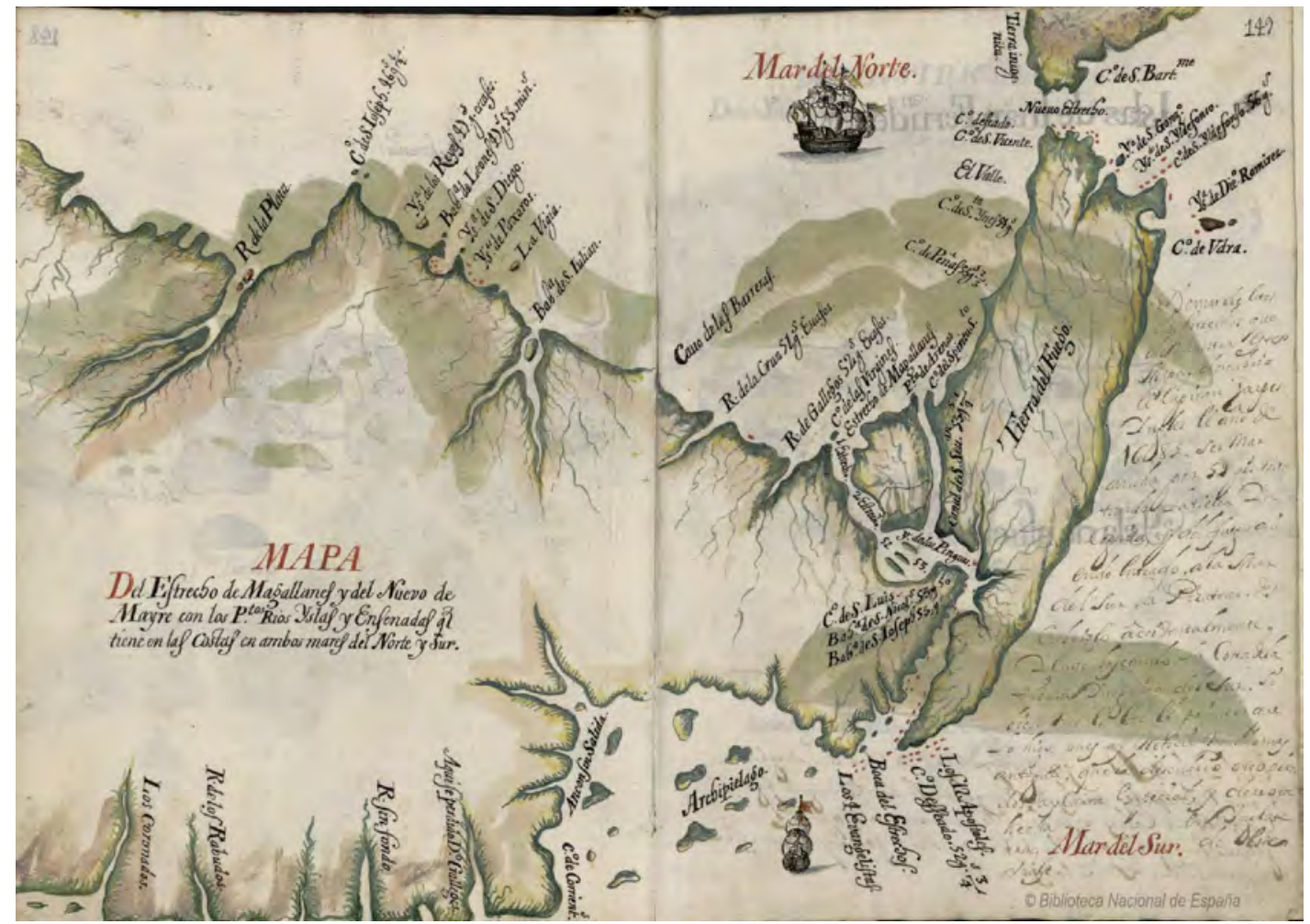

Fig. 4. Mapa de Magallanes y Tierra del Fuego.

Mapas de las costas de América en el Mar del Sur, s. XVII. Biblioteca Nacional de España.

el delineamiento del mapa que para entonces el uso del estrecho Le Maire y el cabo de San Ildefonso era más frecuente en comparación con el estrecho de Magallanes $^{59}$ (Fig. 4).

Precisamente uno de estos derroteros españoles fue capturado por Bartolomé Sharp en 1681 en cabo Pasado, Ecuador, y al regresar a Inglaterra dio origen a las copias que elaboró William Hack. En este caso nuevamente el estrecho de Magallanes, el de Le Maire y el cabo de Hornos seguían teniendo la influencia de los hermanos Nodal, aunque en el caso de Hack, el inglés optó por perseverar en el topónimo neerlandés para el estrecho Le Maire y en el cabo, reemplazando el topónimo por monte de San Ildefonso ${ }^{60}$. Y lo mismo ocurrió en la versión que realizó Basil Ringrose, el cual incorpora todos los topónimos

59 Biblioteca Nacional de España, Mss. 2957, f. 149.

60 A Waggoner of the South Sea describeing the sea coast from Acapulco to Albemarle isle, William Hack, 1685. National Maritime Museum, P/33, f. 147. hispanos de la expedición de los Nodal, pero omite el cabo de San Ildefonso, reemplazándolo por la sierra de San Ildefonso en la misma región que correspondía al referido cabo ${ }^{61}$.

Otros derroteros de origen hispano existentes para el siglo XVII continúan con esta tendencia, siendo el más representativo el que se conserva en la Biblioteca Nacional de España, Derroteros de las costas del Pacífico desde California hasta el estrecho de Magallanes. En el mapa correspondiente a los estrechos estudiados, el autor anónimo lo titula Planta de los estrechos de Magallanes y San Vicente, que comúnmente llaman de Mayre, sacado y reconocido por los dos hermanos llamados Bartolomé y Gonzalo de Nodal, y en él naturalmente se reproduce la ruta del viaje de 1619 hasta el cabo de Udra, al oeste

61 The South Sea Waggoner shewing the making \& bearing of all the coasts from California to the Streights of Le Maire, Basil Ringrose, 1682. National Maritime Museum, P/32, f. 105. 


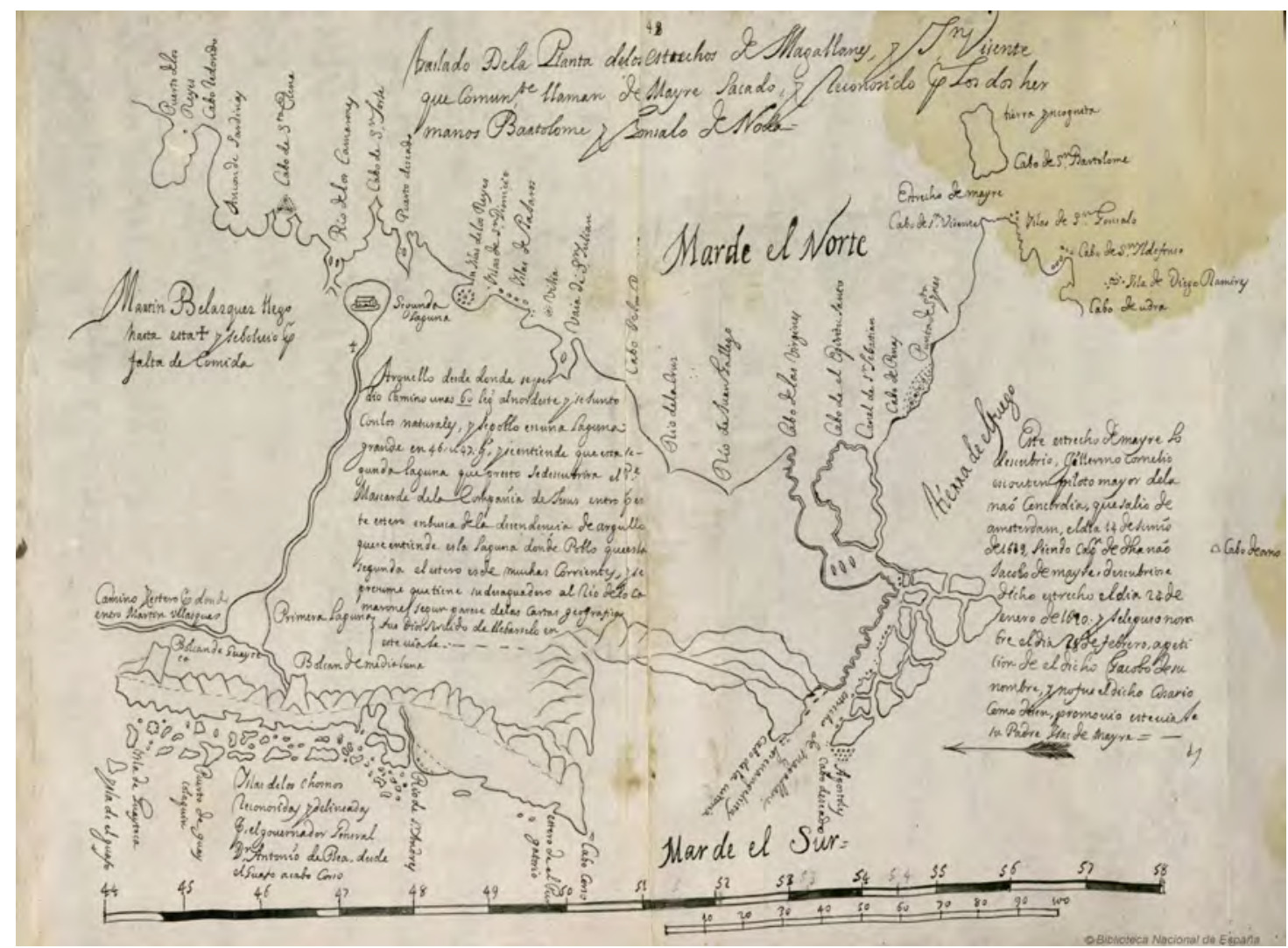

Fig. 5. Planta de los estrechos de Magallanes y San Vicente, que comúnmente llaman de Mayre, sacado y reconocido por los dos hermanos llamados Bartolomé y Gonzalo de Nodal.

Derroteros de las costas del Pacífico desde California hasta el estrecho de Magallanes, s. XVII. Biblioteca Nacional de España.

del cabo de San Ildefonso, tal como está indicado en la edición de $1621^{62}$ (Fig. 5).

En sintesis, la cartografía manuscrita hispana en su versión náutica continuó en el siglo XVII dependiendo de los enormes progresos que se hicieron en tiempos de los hermanos Nodal y de Diego Ramírez, pero es evidente que tras más de medio siglo después, el reconocimiento del territorio austral concentraba grandes deficiencias producidas por la ausencia de cosmógrafos en las expediciones que sortearon ambos estrechos o el cabo de Hornos. Solo como antecedente: en las mismas fechas en que los derroteros antes aludidos eran de uso común

62 Derroteros de las costas del Pacífico desde California hasta el estrecho de Magallanes, Biblioteca Nacional de España, Mss. GMG 1181, f. 48.

63 Moreno, 2013. El estrecho de Magallanes como antesala del Pacífico: evolución cartográfica y toponimia entre los siglos XVI y comienzos del XVIII, Anuario de Estudios entre los pilotos españoles, el capitán inglés John Narborough realizó un levantamiento del estrecho de Magallanes extraordinario para su tiempo ${ }^{63}$, a tal punto que terminó siendo referencia cartográfica para muchos navegantes sin importar la nacionalidad.

Lo que podría sorprender de la imagen anterior es que ese derrotero español, datado hacia 1699, aún dejaba en evidencia el legado cartográfico de aquellos ya lejanos navegantes gallegos de la segunda década del siglo XVII, en especial, gracias a la publicación del famoso mapa realizado por Teixeira, basado en los aportes y delineamientos realizados por los Nodal y Diego Ramírez.

Americanos, 70(2), p. 428. Sobre Narborough y sus objetivos del viaje, cfr. Urbina, 2017. La expedición de John Narborough a Chile, 1670: defensa de Valdivia, rumores de indios, informaciones de los prisioneros y la creencia en la Ciudad de los Césares, Magallania, 45(2), 11-36. 


\section{REFLEXIONES FINALES}

La travesía de los Nodal y Diego Ramírez se sitúa en la paradoja de ser, por una parte, una de las navegaciones más exitosas impulsadas por la corona española a las aguas australes en el siglo XVII, pero por otra, una de las empresas de las que poco recuerdo se guarda, tanto de sus protagonistas como de los resultados y legado de la misma. De hecho, en febrero de 2019, en un aniversario muy silencioso, se cumplieron 400 años del hallazgo de las islas Diego Ramírez, el archipiélago más austral de América, y se terminó por probar empíricamente lo que era una intuición muy avanzada ${ }^{64}$ : la condición insular de Tierra del Fuego, la cual en el siglo XVI había sido frecuentemente identificada como tierra firme, conectada con la mítica Terra australis.

Junto a estas dos proezas que deben ser un hito en la historia de la navegación transoceánica, hay que recordar que al retorno de la expedición a Sanlúcar, sin reportar víctimas fatales, toda una hazaña para aquellos tiempos, se tuvo conocimiento de levantamiento de importantes piezas cartográficas, tanto por parte de los hermanos Nodal como por Diego Ramírez. Sin embargo, en el caso de la que delineó este último, nunca se hizo público pese a que sirvió a Teixeira para realizar el ya comentado mapa impreso de 1621.

Una estrategia de apropiación del territorio por parte de España fue la publicación de la Relación de los hermanos Nodal con el mapa de Teixeira, sin embargo, el silencio de la fuente más importante $e^{65}$, es decir, el escrito científico de Diego Ramírez de Arellano, que solo vio la luz en 1866

64 Martinic, 1998. Drake y el descubrimiento de la insularidad fueguina. La evidencia cartográfica. Anales del Instituto de la Patagonia, 26, 5-22.

65 Ignacio Díaz considera el trabajo de Diego Ramírez como el punto culminante, dentro del dominio hispano [el subrayado es de éll en cuanto al conocimiento de una navegación científica, advirtiendo el valor de su manuscrito pero en un contexto en que España estaba fuera de la génesis de lo que fue la Revolución científica europea de la segunda mitad del siglo XVII. Cfr. Díaz, 2010. Estudio preliminar y transcripción del manuscrito de Diego Ramírez de Arellano, Reconocimiento de los estrechos de Magallanes y San Vicente, con algunas cosas curiosas de navegación (1621). Tesis para optar al grado de Doctor en Historia, Universitat de València, pp. 296-297.

66 La primera edición del derrotero de Ramírez fue publicada y de forma facsimilar impresa en el año 2010 con el mapa original incluido, es una prueba de que faltaron antecedentes para haber consolidado los resultados del viaje de manera tal que el mundo científico internacional, y por ende, la industria editorial de su tiempo, lo hubiera reproducido a otros idiomas y le hubiera reconocido como uno de los estudios cosmográficos más importantes del siglo XVII ${ }^{66}$. De hecho, en la conocida Relación del último viage de la Fragata Santa María de la Cabeza publicada en 1788, el autor aún recordaba que la obra de Diego Ramírez merecía publicarse y ha quedado manuscrita, aunque se divulgaron varias copias incluso entre los extranjeros, dejando entrever que los conocimientos circularon fuera de España, afirmación fundamentada en lo escrito por Seixas y Lovera, pero que hasta ahora no se ha podido probar $^{67}$.

Lo que está claro es que la difusión del manuscrito de Ramírez y su valioso mapa no llegó al mundo editorial y, además, la Relación de los hermanos Nodal solamente tuvo una edición en castellano, no llegando a alcanzar un impacto global, como en cambio sí ocurrió con la obra de Schouten que, por ejemplo, fue publicada en neerlandés en 1618, luego en francés el mismo año y en latín al año siguiente, para posteriormente seguir con ediciones en inglés, alemán y en castellano ${ }^{68}$. Nada de eso sucedió en el caso de los Nodal, y con el agravante de que la fuente, que hubiese sido un gran golpe científico para su tiempo, la de Ramírez, permaneció inédita hasta el siglo XIX.

Sin embargo, pese a que el objetivo de apropiación geográfica del territorio a través de los topónimos no se pudo lograr, en cuanto al

en 1866. Cfr. Depósito Hidrográfico de la Marina, 1866. Discurso y derrotero del viaje que se hizo a los estrechos de Magallanes y de San Vicente, por Diego Ramírez de Arellano, Anuario de la Dirección de Hidrografía Año IV Depósito Hidrográfico, Imprenta de T. Fortanet, Madrid, pp. 206-291. Cfr. Rodríguez, 2018, op. cit., p. 314, nota 40.

67 Vargas Ponce, 1788. Relación del último viage al estrecho de Magallanes de la Fragata de S. M. Santa María de la Cabeza en los años 1785 y 1786: extracto de todos los anteriores desde su descubrimiento impresos y MSS. y noticia de los habitantes, suelo, clima y producciones del estrecho. Imprenta de la viuda de Ibarra, Hijos y Compañía, Madrid, p. 260. Cfr. Seyxas y Lovera, 1690. Descripcion geographica, y derrotero de la region Austral Magallanica..., Antonio de Zafra, Madrid, pp. 10-10r.

68 Moreno, 2013, op. cit., p. 38. 
rápido arraigo de los nombres neerlandeses, en especial el estrecho Le Maire y el cabo de Hoorn, algunos espacios reconocidos en forma pionera por los navegantes hispanos, como por ejemplo, las islas Diego Ramírez y la bahía del Buen Suceso, sí fueron aceptados y reproducidos por la ciencia cartográfica europea, proyectándose en el tiempo hasta nuestros días ${ }^{69}$.

Ahora bien, consideramos que en el paulatino olvido de estos expedicionarios y, por ende, su gesta náutica, pudo influir el que los hermanos Nodal murieron ambos en 1622 en sendos naufragios, es decir, al año siguiente de la publicación de su obra, y que Diego Ramírez, como Piloto Mayor de la Casa de Contratación pudo llegar a ser una persona muy influyente, murió apenas dos años más tarde. Esto hizo que los protagonistas de la empresa, llamada a ser un referente para las futuras navegaciones, no alcanzaran a consolidar lo realizado pese que, a diferencia de otras expediciones, en ésta se había llegado a la imprenta muy pronto, aunque sin repercusiones a largo plazo, al menos en las traducciones internacionales $\mathrm{o}$ en nuevas ediciones. De hecho, la segunda edición de la obra solo vio la luz en el año 1766, con el mismo mapa de Teixeira incluido, pero para entonces, más que una contribución científica en tiempos de la marina ilustrada, se trataba de la reedición de un clásico que estaba completamente superado en cuanto a conocimiento geográfico se refiere ${ }^{70}$.

No obstante lo anterior, en donde sí influyó la expedición de los hermanos Nodal y Diego Ramírez fue en la cartografía náutica hispana del siglo XVII, en particular el mapa de 1621, en donde el conocimiento y delineamientos realizados por los viajeros influyeron notoriamente en la elaboración de derroteros náuticos, los que circulaban en manos de los pilotos hispanos del Mar del Sur. En dichos mapas se evidencia una importancia mayor del estrecho de San Vicente y del cabo de San Ildefonso por sobre el estrecho de Magallanes

69 Una interesante visión es la que plantea David Rodríguez Couto, quien advierte la importancia de la expedición en el contexto político donde la idea del dominio de los mares estaba presente, por lo que este concepto de apropiación cobraría mucho sentido. Rodríguez, 2018, op. cit.

70 La obra fue reimpresa por orden de Joaquín Manuel de Villena, Marqués del Real Tesoro, quien además de ser miembro del Consejo de S.M., era Jefe de Escuadra, Presidente de la Real en cuanto a descripción toponímica, en un siglo XVII y comienzos del XVIII donde la navegación hispana por el sur se hizo poco frecuente, sí fue utilizado por algunos como, por ejemplo, Francisco Seixas y Lovera quien en su célebre Descripcion Geographica reconoce haber pasado dos veces hacia el Pacífico y otra vez de regreso al Atlántico por lo que él denomina "Pasage de El Mayre"71. Pero aún más frecuente fue la presencia de expediciones neerlandesas, inglesas y francesas ${ }^{72}$, las que terminaron por ratificar la toponimia de la expedición de Schouten y Le Maire.

\section{AGRADECIMIENTOS}

Proyecto (I+D+i) FFI2015-65007-C41-P, "La herencia clásica. Descripciones y representaciones del Mundo Hispánico, siglos XVIXIX".

\section{BIBLIOGRAFÍA}

Cerezo, R. (1994). La cartografía náutica española en los siglos XIV, XV y XVI. Madrid: Consejo Superior de Investigaciones Científicas.

Díaz, I. (2010). Estudio preliminar y transcripción del manuscrito de Diego Ramírez de Arellano "Reconocimiento de los estrechos de Magallanes y San Vicente, con algunas cosas curiosas de navegación" (1621). Tesis para optar al grado de Doctor en Historia, Valencia: Universitat de València.

Díaz, I. (2013). Aportaciones al cálculo de la latitud en la náutica española de principios del siglo XVII contenidas en el manuscrito de Diego Ramírez de Arellano Reconocimiento de los estrechos de Magallanes y San Vicente, con algunas cosas curiosas de navegación (1621). Asclepio. Revista de Historia de la Medicina y de la Ciencia, 65(2), 1-14.

Esteban, M. (2002-2003). Las academias técnicas en la España del siglo XVI. Quadern's d'Historia de I’Enginyeria,

Audiencia y de la Casa de Contratación. La edición estuvo a cargo de Manuel Espinoza de los Monteros, que era el impresor de la Real Armada en Cádiz.

71 Seyxas y Lovera, 1690, p. 65r.

72 Gentinetta, 2018. La Armada del Mar del Sur: reforma para asegurar los territorios en el nuevo contexto geopolítico de principios del setecientos, Cuadernos de Historia. Serie economía y sociedad, 20, 123-153. 


\section{V, 10-18.}

Fernández de Navarrete, M. (1851). Biblioteca Marítima Española. Madrid: Imprenta de la viuda de Calero.

Firbas, P. (2012). El mapa y sus sombras: La Relación de los hermanos Nodal al Estrecho de Magallanes (1621). En Faúndez V. y Lermanda, O. (Eds.), El laberinto y el hilo. Homenaje a Gilberto Triviños. Concepción: Editorial Universidad de Concepción, 32-51.

Gentinetta, M. (2018). La Armada del Mar del Sur: reforma para asegurar los territorios en el nuevo contexto geopolítico de principios del setecientos, Cuadernos de Historia. Serie economía y sociedad, 20, 123-153.

Gil, J. (1989). Mitos y utopías del Descubrimiento. Madrid: Alianza editorial. Tomo II: El Pacífico.

Guillén y Tato, J. (1940). Una carta inédita del estrecho de Le Maire e identificación de otras dos anónimas del siglo XVI, Revista de Indias, I, 35-58.

Guillén y Tato, J. (1942). Monumenta Chartographica Indiana. Madrid: Ministerio de Asuntos Exteriores.

Harley, J. B. (2005). La Nueva Naturaleza de los Mapas. Ensayos sobre la Historia de la Cartografía. México: Fondo de Cultura Económica.

Kroon, P. (Ed.) (2016). Atlas of Cape Horn. The cartography of Southern South America 1500-1725. Bussum: Thoth Publishers.

Lach, D., \& Van Kley, E. (1993). Asia in the making of Europe. Chicago: Chicago University Press.

Martinic, M. (1972). Cartografía derivada de los descubrimientos y exploraciones holandeses en la región Magallánica. Comentario y catálogo preliminar. Anales Instituto de la Patagonia, 3(1-2), 5-30.

Martinic, M. (1998). Drake y el descubrimiento de la insularidad fueguina. La evidencia cartográfica. Anales del Instituto de la Patagonia, 26, 5-22.

Martinic, M. (1999). Cartografía Magallánica 1523-1945. Punta Arenas: Ediciones de la Universidad de Magallanes.

Martinic, M. (2018). Cuatro siglos del viaje de los hermanos Nodal a la Tierra del Fuego. Magallania, 46(2), 7-23.

Moreno, R. (2013). El estrecho de Magallanes como antesala del Pacífico: evolución cartográfica y toponimia entre los siglos XVI y comienzos del XVIII. Anuario de Estudios Americanos, 70(2), 419-439.

Moreno, R. (2013). El cabo del Fin del Mundo: Hoorn y el camino al Pacífico. En Guerra, S. (Ed.), Enigmas de las Américas. Geografía, Expediciones, Cartografía. Quito: Universidad de San Francisco, pp. 35-43.

Moreno, R. y Ortiz, J. (2018). Un Derrotero del Mar del Sur. El Pacífico americano a fines del siglo XVII. Santiago:
Biblioteca Nacional, Centro de Estudios Barros Arana.

Ortiz, J. (Ed.) (1993). Derrotero General del Mar del Sur del capitán Pedro Hurtado de Mendoza, hecho por el Capitán Manuel Joseph Hurtado en el puerto del Callao, año 1730. Lima: Dirección de Intereses Marítimos.

Portela, F. (1891). Apuntes biográficos acerca de los marinos Nodales, hijos de Pontevedra. Pontevedra: Imprenta Landín.

Pulido, J. (1950). El Piloto Mayor. Pilotos mayores, catedráticos de cosmografía y cosmógrafos de la Casa de Contratación de Sevilla. Sevilla: Escuela de Estudios Hispano Americanos.

Rodríguez, F. (2017). Expedición de los Hermanos Nodal y el cosmógrafo Diego Ramírez: el fin del ciclo de los grandes descubrimientos en los mares del Sur. Tesis para optar al grado de Magíster en Historia. Santiago: Universidad Adolfo Ibáñez.

Rodríguez, D. (2018). El poder está en el Mar. La expedición de los Hermanos Nodal (1618-1619). Obradoiro de Historia Moderna, 27, 293-320.

Urbina, X. (2017). La expedición de John Narborough a Chile, 1670: defensa de Valdivia, rumores de indios, informaciones de los prisioneros y la creencia en la Ciudad de los Césares. Magallania, 45(2), 11-36.

Vázquez de Acuña, I. (1996). La expedición de los hermanos Nodal (1618-1619). Boletín de la Academia Chilena de la Historia, 106, 31-51.

Vicente, M. I. (2001). La expedición de los hermanos Nodal y el cosmógrafo Diego Ramírez de Arellano. Revista de Historia Naval, 73, 7-28.

Zuleta, J. (2013). La fortificación del estrecho de Magallanes: un proyecto al servicio de la imagen de la monarquía. Revista Complutense de Historia de América, 39, 153-176.

\section{FUENTES}

Depósito Hidrográfico de la Marina (1866). Discurso y derrotero del viaje que se hizo a los estrechos de Magallanes y de San Vicente, por Diego Ramírez de Arellano. Anuario de la Dirección de Hidrografía, Año IV, 206-291.

Nodal, B. y Nodal, G. (1621). Relación del viaje que por orden de su Mag. y acuerdo del real Consejo de Indias hizieron los capitanes Bartolomé García de Nodal y Gonzalo de Nodal... al descubrimiento del Estrecho nuebo de S. Vicente y reconosimiento del de Magallanes. Madrid: Imprenta de Fernando Correa.

Ramírez de Arellano, D. (2010). Reconosimiento de los 
Estrechos de Magallanes y de San Viçente. Valencia: Institució Alfons el Magnàmin. Edición facsimilar del manuscrito de 1621. Introducción de Emilio Soler, I, 21-243.

Schouten, W. (1618). Journal Ofte Beschryvinghe van de wonderlicke reyse, ghaedaen door Willem Cornelisz Schouten van Hoorn, inde Jaren 1615, 1616, en 1617. Hoe hy bezuyden de Strate van Magekkanes een nieuwe Passagie tot inde groote Zuyzee onteckt en voort den gheheelen Aerdkloot angheseylt, heeft. Wat Eylanden, ureemde volcken en wonderlicke avontueren hem ontmoet zijn. Amsterdam: Willem Jansz.

Seixas y Lovera, F. (1690). Descripcion geographica, y derrotero de la region Austral Magallanica... Madrid: Antonio de Zafra.

Vargas Ponce, J. (1788). Relación del último viage al estrecho de Magallanes de la Fragata de S. M. Santa María de la Cabeza en los años 1785 y 1786: extracto de todos los anteriores desde su descubrimiento impresos y MSS. y noticia de los habitantes, suelo, clima y producciones del estrecho. Madrid: Imprenta de la viuda de Ibarra, Hijos y Compañía. 